\title{
De la injusticia al fracaso: La experiencia del paro en un grupo de jóvenes de Madrid
}

\author{
ANA M. ${ }^{a}$ RIVAS RIVAS \\ Departamento de Antropología Social \\ Facultad de CC. Políticas y Sociología \\ Universidad Complutense. Madrid
}

En España, según la Encuesta de Población Activa correspondiente al tercer trimestre de 1998, la tasa de desempleo entre la población juvenil era de $43,7 \%$ para los jóvenes de 16 a 19 años; de 32,1\% para los de 20 a 24 años y de $24,0 \%$ para los de 25 a 29 años. Todas ellas por encima de la tasa nacional de desempleo, situada en el $18,5 \%$ para el mismo período del año. Pero mi análisis no se va a centrar en el aspecto cuantitativo del paro entre los jóvenes, sino en intentar comprender y explicar cómo es posible que con este elevado porcentaje de parados entre la población de 16 a 29 años, no se haya producido en la sociedad española una movilización social, política y sindical de este colectivo que haya cuestionado un mercado laboral y unas políticas económicas que hacen de los jóvenes eternos aspirantes a un puesto de trabajo, residuos sometidos a un proceso continuo de reciclaje: de estudiantes a becarios, de becarios a voluntarios, de voluntarios a aprendices, de aprendices a contratados temporales, de temporarios a desempleados, de parados a cursillistas y vuelta a empezar.

Mi propósito es ahondar en algunos de los mecanismos ideológicos de sometimiento y disciplinamiento de este colectivo, que explican su despolitización y antisindicalismo; su falta de combatividad y de lucha por transformar unas condiciones de existencia que los han "envejecido" prematuramente, instalándolos en un estado vivencial donde no tienen cabida las esperanzas ni las ilusiones; su consentimiento e interiorización de una situación personal y social que se les presenta como algo inevitable, a la que deben doblegar su voluntad y libertad si quieren obtener un empleo, sea el que sea y en las condiciones que sea.

Varios son los dispositivos que pueden ser considerados como neutralizadores del potencial conflictivo que supone tener un número tan elevado de jóvenes en paro. Uno de ellos la institución familiar, institución utilizada por las políticas económicas neoliberales para dar cumpli- 
miento a la máxima de socializar las pérdidas y privatizar los beneficios. A la familia se le ha asignado en este sentido la función de asumir los costes sociales de la flexibilización y desregulación del mercado laboral, lo que explica la larga permanencia de los jóvenes en el hogar de los padres, tal y como muestra el informe sobre la juventud de 1996 (Martín Serrano y Velarde), según el cual sólo el $18 \%$ de los jóvenes hasta 30 años estaba emancipado de su familia y sólo el $16 \%$ de los jóvenes de 15 a 29 años vivía exclusivamente de sus propios recursos; así se explica también la importancia del trabajo "invisible" de los abuelos, que hace posible que las parejas jóvenes puedan compatibilizar su actividad profesional con un proyecto matrimonial y con sus funciones parentales y maternales (Rivas 1999).

Además de las redes familiares, existen otras agrupaciones sociales como organizaciones no gubernamentales y asociaciones de voluntariado, que están actuando como amortiguadores de las tensiones larvadas en los jóvenes desempleados, quienes ven en estas organizaciones un nuevo tipo de oportunidades para realizar prácticas y engrosar así sus curricula. El paso por una ONG forma parte actualmente del proceso de inserción laboral de muchos jóvenes que, al terminar su formación universitaria o profesional, utilizan estas asociaciones como lugar donde adquirir experiencia, establecer contactos y explorar los "nuevos yacimientos de empleon.

Junto a estos dispositivos disuasorios de potenciales conflictos, están las propias condiciones de acceso al mercado laboral (rotación, transitoriedad, inestabilidad) que afectan muy especialmente a los jóvenes. Sólo basta echar un vistazo al perfil de los contratados por las empresas de trabajo temporal durante 1998: la edad media de los trabajadores cedidos fue de 26,8 años, teniendo más de la mitad de los contratados entre 16 y 24 años; los jóvenes entre 16 y 29 años representaron el $74 \%$ del total de la contratación, concentrándose los más jóvenes en los contratos a tiempo parcial y por necesidades de la producción. Un dato clave para comprender el grado de precarización al que se ven sometidos los jóvenes que acuden a las ETTs es la duración de los contratos. En el mismo año de 1998, el 36\% de los contratos fueron de duración indeterminada por tratarse de obra o servicio, o por interinidad. En los restantes, el 64\%, básicamente aquéllos que se formalizaron por necesidades de la producción, el 31\% duraron menos de cinco días; de cinco días a un mes el 26\%; de uno a dos meses el 4\%; de dos a cinco meses el $2 \%$ y más de cinco meses el 1\% (Rojo Torrecilla 1999: 179-180).

Teniendo como telón de fondo los hechos anteriores, el objetivo de este artículo será el análisis de uno de los mecanismos ideológicos que 
actúan como dispositivo inhibitorio de la movilización de los jóvenes desempleados: la estructura metafórica del sistema conceptual a través del cual estos jóvenes construyen un marco de percepción, explicación y comprensión de su situación laboral, en función del cual articulan sus estrategias y prácticas en la búsqueda de trabajo.

Para ello, voy a analizar los relatos extraídos de cuatro grupos de discusión, realizados durante los años 1997 y 1998 con jóvenes desempleados de un barrio de Madrid (Barrio del Pilar), perteneciente al distrito de Fuencarral. El número de participantes en los grupos de discusión osciló entre 3 y 5 , sumando un total de 14, entre los que había 6 chicas y 8 chicos, de edades comprendidas entre 19 y 35 años; algunos habían tenido ya alguna experiencia laboral y otros ninguna; 5 tenían estudios superiores, 1 hasta $3 .^{\circ}$ de Formación Profesional, 2 hasta COU y 6 hasta 3. ${ }^{\circ}$ de BUP.

De los discursos de estos jóvenes destacan dos hechos que llamaron mi atención y que en el esfuerzo por comprenderlos y entenderlos me decidieron a aplicar el análisis metaforológico de G. Lakoff y M. Johnson (1991). Por un lado, me sorprendió la ausencia en sus narraciones de conceptos representativos de valores clave por medio de los cuales otras generaciones - la de sus padres, la mayoría trabajadores de la industria y de la construcción - configuraron sus experiencias laborales: solidaridad, unidad, justicia, igualdad, asociacionismo, esperanza, futuro mejor... En su lugar, términos como éxito, fracaso, competencia, suerte, fortuna, valía personal, formación... aparecían reiteradamente en sus explicaciones. Por otro lado, me desconcertó el fatalismo, el desencanto y la decepción que transmitían a través de sus intervenciones; es posible comprender la desmoralización de los que, después de luchar por hacer realidad sus ideales (para lo cual primero hay que tenerlos), son vencidos por sus oponentes, o engañados por sus correligionarios ${ }^{1}$, pero ¿cómo entender el desencanto de aquéllos que sin experiencia de militancia ni de lucha social o política se sienten ya derrotados?

1 Este es el tipo de desmoralización que se percibe en informantes de la generación anterior a estos jóvenes, militantes de partidos políticos, sindicatos y asociaciones vecinales, que participaron activamente en el movimiento social del barrio conocido como "La Vaguada es nuestra", cuyo objetivo era impedir la construcción de una superficie comercial en una zona que reivindicaban para servicios y espacios verdes para el vecindario, uno de los más poblados de Madrid. A pesar de las promesas del partido socialista de paralizar el proyecto si ganaba las elecciones municipales de Madrid de 1982, el centro comercial fue construido e inaugurado en 1983 con los socialistas en el poder municipal, hecho que fue interpretado por el movimiento asociativo como un engaño y una traición al sentir popular. 
Para responder a estas cuestiones, a partir de los discursos de los entrevistados, encontré de gran utilidad metodológica las propuestas analíticas de G. Lakoff y M. Johnson sobre la naturaleza metafórica de nuestro sistema conceptual ordinario, en términos del cual pensamos y actuamos. Según estos autores (ibid: 91), el lenguaje nos proporciona información, datos, acerca de la forma en que la gente entiende sus experiencias, lo que ellos llaman "principios generales de la comprensión", principios que implican "sistemas totales de conceptos" más que palabras sueltas o conceptos individuales; sistemas conceptuales de naturaleza fundamentalmente metafórica, que suponen la comprensión de un tipo de experiencia en términos de otro tipo de experiencia. La metáfora, al ser una manera de concebir una cosa en términos de otra, nos ayuda a entender y comprender la realidad, a dar coherencia y sentido a nuestra experiencia cotidiana, a sabernos conducir por ella; nos ayuda a crear expectativas y aspiraciones coherentes con esa realidad; sirve como guía para nuestro comportamiento, conducta y experiencias futuras. Por lo tanto, el poder de las metáforas no está sólo en su función comprehensiva y referencial de la realidad, sino también en su capacidad de determinar lo que es real para nosotros, al configurar y articular nuestras representaciones internas y nuestra visión del mundo; según nos representamos y pensamos el mundo, así actuamos sobre él; según percibimos y estructuramos nuestra experiencia, así adquirimos compromisos y ejecutamos planes de actuación sobre ella, así nos movemos en el mundo y nos relacionamos con otras personas (ibid: 186-188).

De ahí la importancia de revelar la estructura metafórica de todo discurso y, en concreto, del discurso de los jóvenes sobre sus vivencias de parados.

$\mathrm{Al}$ analizar desde esta perspectiva los relatos de los participantes en los grupos de discusión, apareció un elemento recurrente, expresado a través de figuras ya lexicalizadas en el lenguaje ordinario y cotidiano. Estas expresiones eran dominantes en la descripción que hacían de los condicionamientos, dificultades, posibilidades, recursos disponibles, a la hora de incorporarse a un puesto de trabajo. Veamos algunos ejemplos:

"[...] es que en estos momentos son muchas cosas, no sabes lo que te toca, a lo mejor te sale un trabajo y qué alegría y resulta que es un contrato de seis meses y adiós"; "hay que tener suerte para tener un puesto de trabajo fijo"; "mis padres están preocupados porque hoy en día el tener un trabajo estable, un contrato indefinido, como dice mi padre, es un tesoro, un trabajo fijo es un tesoro y como ven que ahora las cosas se están poniendo muy mal..."; "mi padre entró en la fábrica cuando tenía 23 años y se ha jubilado en la misma empresa y eso ahora no es así, que entres joven y y te jubiles en la misma empresa, eso es como que te toque la loteria ; atal y como está la situación hay que coger lo primero que te 
sale, es que no puedes ni elegir, te sale una cosa y o lo aprovechas o lo pierdes; "yo tengo la suerte de tener unos padres que me ayudan, pero ¿hasta cuándo va a poder durar esto?, imagínate que a tu padre le despiden mañana"; "también puedes montarte un negocio, pero que te salga bien, que no es fácil, sino bastante difícil, tienes que trabajar como un condenado y lo más probable es que te salga mal $[\ldots]^{n}$

El elemento recurrente que impregna los discursos de los informantes es la idea de que acceder o no a un puesto de trabajo no depende tanto de ellos como de un factor ajeno a su voluntad, de un azar probabilístico que escapa al control humano: "la suerte. Idea reforzada a través de las expresiones que he destacado en cursiva en las citas anteriores: "tener suerte", "tocar la lotería", "encontrar un tesoro", "no poder elegir", "salir al encuentro", "salir bien", "salir mal", "perder" ${ }^{2}$.

A estas expresiones lexicalizadas que hacen referencia a situaciones de "suerte", hay que añadir otro conjunto de fórmulas, derivadas esta vez de situaciones de "juego":

“[...] para nuestros padres la profesión era para siempre, el mercado laboral se movía de una forma lenta, ahora va tan acelerado, que cualquiera está fuera de juego en tres meses con la revolución tecnológica y el nuevo mercado de trabajo y los nuevos contratos y la leche en vinagre..."; "la familia está al quite, yo creo que ahí sí que hay reglas, es decir, no hay una intromisión, hay una relación de quite, es decir, si hay un problema están ahí, si no hay problemas, la frase de mi madre 'hijo si vas bien, yo tranquila, yo, yo no necesito nada'"; "para buscar trabajo hay que moverse mucho, te tienes que mover todos los días, levantarte por la mañana y a la calle"; "nadie nos va a buscar trabajo, uno tiene que viajarse, es muy importante estar en relaciones, conocer a otra gente que ha encontrado cosas, cómo lo ha hecho, qué se le ocurrió, qué utilizó, a qué recursos acudió y eso nos da pistas para saber nosotros por dónde ir, porque a lo mejor nos estamos poniendo a buscar cosas que son imposibles porque ni tenemos preparación o son terrenos que están demasiado trillados y deberíamos buscar por otros lados"; "más triste que nosotros que estamos buscando nuestro primer trabajo es la gente que jubilan con 44 años y tienen una familia que mantener, una casa, te das cuenta de que eso tiene que ser tristísimo... no es que nosotros no hayamos encontrado nuestro primer trabajo, sino que después te pueden jubilar, o quedarte sin jubilación, está todo en el aire, todo en el aire; "pues hombre siempre que tienes un trabajo te llena en muchos sentidos, te abre más puertas en todo, conoces gente, eso también te ayuda a abrirte otros caminos [...]"

2 J. García Montalvo y J. M. ${ }^{a}$ Peiró, en un estudio realizado sobre la inserción laboral de los jóvenes valencianos, señalan también la importancia que los jóvenes atribuyen a "la suerte" cuando se trata de acceder a un empleo (La inserción laboral de los jóvenes de la Comunidad Valenciana” en Cachón 1999: 206). 
Las expresiones fijas señaladas en cursiva en el texto y otras que aparecen a lo largo de los diálogos están construidas a partir de nuestro sistema conceptual referente a la cultura lúdica, ya sea inspiradas en el juego de naipes: "mover (carta)", "salir bien o mal (una jugada)", "abrir (juego)", "estar fuera de juego", "estar todo en el aire (como un castillo de naipes)", "no saber por dónde tirar", "estar al quite", "aprovechar (la jugada)"; ya sea en el juego de pistas, que consiste en esconder un objeto (tesoro, prenda), pensar en algo o en alguien y ayudar a encontrarlo, o averiguar de qué se trata ofreciendo señales o indicios: "buscar", "dar pistas", "recorrer un terreno trillado", "viajarse"...

Las dos metáforas literales "suerten y "juego" de las que se derivan las expresiones lexicalizadas, utilizadas en el lenguaje ordinario y cotidiano de estos jóvenes desempleados, están estructuradas por un concepto metafórico básico, que da coherencia a la forma de percibir, hablar y experimentar la situación del desempleo: la vida es sentida como un ajuego de azar" y acceder a un trabajo, como "un golpe de suerte". El concepto metafórico estructural "juego de azar" permite comprender y entender un dominio fundamental de la experiencia humana como es el laboral y, consiguientemente, permite explicar el éxito o fracaso que en él se tenga.

La utilización de esta metáfora básica por parte de los entrevistados se debe a que el concepto definidor —una situación de juego- se ajusta al concepto definido -incorporación al mercado laboral- y a la vivencia de emociones y sentimientos que se quieren transferir -incertidumbre, inestabilidad, inseguridad, riesgo, falta de dominio de la situación, desposesión, dependencia y subordinación a circunstancias que no se pueden prever ni evitar. En este caso, la eficacia de la metáfora consiste en la semejanza estructural de aquello que destaca - la probabilidad de ganar o perder, de encontrar o no lo que se busca- con la experiencia personal y colectiva de los que por "buscar" trabajo y no "encontrarlo" se sienten como "perdedores".

Pero ya dijimos al principio que el poder de la naturaleza metafórica del lenguaje no está sólo en su función referencial y comprehensiva, sino también en su capacidad de orientar nuestro comportamiento, conducta y experiencias futuras, al determinar lo que es real para nosotros. Y lo que en principio es una "idea" con la que se pretende legitimar un sistema económico que ya no necesita de la intensificación del trabajo humano para la extracción y acumulación de beneficios, acaba convirtiéndose en lo "real" para los activos con empleo o sin empleo: la representación del trabajo como un bien escaso. Los que lo tienen han de conservarlo a toda costa, los que no lo tienen han de desplegar todos sus recursos para encontrarlo, sabiendo que son muchos los que van a competir por un bien que al 
ser escaso aumenta su valor. De ahí a considerar un empleo como un "tesoro", "un golpe de fortuna", hay sólo un paso. Paso que es fácil dar en un contexto ideológico en el que la misma economía, en su versión de libre mercado, se presenta como una instancia desgajada de lo político y lo social, con sus propias leyes, independientes de la voluntad humana, cuya intervención se debe evitar para no interferir ni distorsionar el desarrollo del "mercado", dando lugar a una situación en la que hemos pasado de una economía de mercado a una sociedad de mercado, como muy bien muestran los análisis de Polanyi (1989) y De Lucas (1994).

Uno de los jóvenes participantes en los grupos de discusión reflejaba esta idea de que mientras todos nosotros dependemos de la economía, puesto que la propia persona es percibida como un producto más, la economía no parece depender nada más que de ella misma:

Tú eres un producto más y tienes que ofertar a las empresas, nosotros lo que podemos poner de nuestra parte es el estudiar y dar lo que quieren las empresas, pero eso tampoco depende de nosotros sino de cómo va la economía del país...

La interiorización de este discurso por parte de la población juvenil en paro y, sobre todo, del principio, transformado en axioma y verdad absoluta, del trabajo como bien escaso, está en el origen de la percepción y definición de su situación vital y laboral como "juego de azar".

Si encontrar o no trabajo no depende tanto de los sujetos como de circunstancias de azar, cuando alguien lo intenta una y otra vez sin obtener resultados positivos, el razonamiento lógico al que, necesariamente, induce esta situación es el siguiente: no tener suerte, repetidamente, le convierte a uno en un perdedor, por lo tanto, en una persona fracasada, y si hay otros que, por el contrario, sí consiguen acceder a un trabajo, la pregunta es "ipor qué los demás y yo no?", "iserá que yo no valgo?"; con lo que una situación como el desempleo, que en principio responde a causas estructurales derivadas del modelo económico dominante en la sociedad a la que pertenecen los entrevistados (independientemente del ámbito al que nos refiramos, puesto que tanto en el ámbito local, autonómico, estatal o europeo el modelo es el mismo), acaba transformándose por un proceso de naturalización en un problema de "valía personal":

"[...] es que llega un momento que hasta no te apetece salir y te quedas como si fueras un torpe, un inútil, como si uno no supiera bacer nadan; "gente que no tiene ni EGB y se coloca, es que no lo entiendo...; ; yo de tanto que he intentado es que ya no sé ni qué hacer, es que ya hay veces que voy a buscar trabajo pero por ir, pero sin ganas ni nada... porque te han prometido tanto que sí que te van a llamar, que sí que les has gustado y luego estás esperando la llamada y no te 
llaman...; ;es que hay gente que tiene muchos estudios, muchas carreras y también están en el paro..., es que tener un título de universidad no quiere decir que ya vales, hay gente que tiene muchos títulos y que no vale, es que tampoco hay que ser nada especial para sacarse un título de universidad, sino que hay que estar motivado y tener ganas de estudiar, eso está claro, pero indudablemente no sólo el que tiene el título sino el que vale termina consiguiendo un trabajo, no es como cuando nuestros padres que el que tenía una carrera se comía el mundo, es que, es que las cosas cambian, ahora todo el mundo tiene carrera y no todo el mundo puede ser el primero, sólo el que vale, vale..."

La imagen del trabajo como un recurso escaso y valioso refuerza este proceso de naturalización, legitimado, a su vez, por el discurso de los expertos, quienes utilizan una expresión metafórica, coherente con el sistema conceptual dominante entre los jóvenes en paro, para definir las nuevas actividades y sectores creadores de empleo: “los nuevos yacimientos de trabajon.

El término "yacimiento" en su acepción geológica, hace referencia a la acumulación natural de una sustancia mineral o fósil, utilizable como materia prima o como fuente de energía, que puede encontrarse en el subsuelo o en la superficie terrestre y cuya durabilidad es limitada. El uso metafórico de este término utilizado por los estudiosos y que tan buena acogida ha tenido entre los medios de comunicación, sanciona positivamente la imagen del mercado laboral como un lugar donde escasean los empleos, y confirma la visión de la trayectoria laboral de una persona como una constante búsqueda y permanente sucesión de contratos, cuya duración no se puede asegurar. El empleo se compara con una sustancia mineral, que aparece y se agota con su extracción, existiendo nuevos filones y vetas que hay que buscar, encontrar y explotar, pero ello no depende de la voluntad del hombre ni de la sociedad, sino de la disposición natural de los elementos geológicos; al igual que las sustancias minerales y fósiles están en la naturaleza, pero hay que saber dar con ellas, los empleos existen pero hay que saber dar con ellos, para lo que hay que utilizar todos los recursos a nuestro alcance.

Quizás así se pueda entender por qué las políticas de empleo y la mayor parte de los cursos destinados a los parados están orientados a la formación del trabajador, al aprendizaje de técnicas de búsqueda de empleo, a la elaboración del curriculum, al asesoramiento de imagen, a saber responder a las entrevistas de trabajo, etc., dando por supuesto, que las causas del desempleo están, especialmente, en la persona del trabajador y no en la estructura económica ni en los otros actores que intervienen en el proceso económico, como los propietarios del capital industrial o financiero. 
Si el problema se plantea en términos individuales, de valía personal de los que "buscan" trabajo, también la solución coherente debe ser en términos individuales, activando los recursos de que dispone cada uno: primero recurriendo a la formación y a las dotes y cualidades personales.

"Yo hice hasta $3 .^{\circ}$ de FP, porque era una cosa que no me gustaba mucho lo que estaba haciendo, yo lo que quería era trabajar, pero es que hice una tontería porque para como está el trabajo, el trabajo es que está muy mal y entonces bueno, me salió un trabajo de limpieza pero un mes, luego hice un curso del INEM, Secretariado de Dirección, que eran cinco o seis meses y nada, ahora estoy en una academia buscando trabajo, a ver si sale algo..."; "yo dejé de estudiar cuando terminé $3 .^{\circ}$ de BUP y he hecho inglés, informática, algunos cursos de marketing y tal, pero nada...,; "yo creo que es muy importante lo de la preparación laboral pero no sólo en estudios y en formación sino en lo personal, la disposición de cara a trabajar con otra gente, la disponibilidad que uno tiene y uno muestra, porque claro es verdad que una cosa es encontrar un trabajo, pero luego hay que mantenerlo, y mantenerlo ya no es tanto por lo que uno haya estudiado y aprendido, sino es más por lo que uno es capaz de poner de lo suyo, de sus valores para que eso siga adelante... y eso es muy importante..

Segundo, movilizando las redes de parientes, amigos, conocidos y vecinos.

"Aunque tus padres quieran ellos no te pueden colocar, mis padres hacen todo lo posible, pero no conocen a nadie que me pueda colocar, yo tengo amigas que sí que cuando acaban los estudios ya están colocadas, mi madre intenta hacer lo posible, habla con gente, me aconseja, pero no hay manera... yo tengo una amiga, que acabó la FP y su padre le montó una tienda y ya está trabajando y tengo otra también que está estudiando y tiene un cuñado que también tiene una empresa y la va a colocar y yo veo eso y es que... me da yo qué sé, que a ellas las puedan colocar y a mí no me coloca nadie"; "yo tengo amigos desde los que sólo tienen octavo a gente que ya ha terminado su carrera... o sea de todas las clases, lo que está claro es que a medida que estudias más te va mejor, y para mí que la mayoría de la gente que tiene carrera el ambiente familiar y social que han tenido ha sido más propicio para estudiar, las familias que les faltan recursos, dinero, con situaciones conflictivas, pues no educan al hijo lo suficiente, más cuando faltan los medios... eso es lo más triste que hay gente que nace ya limitada por mucho que quieran, cuantos más recursos tienes más suerte tienes que tener".

La acción colectiva como respuesta al desempleo no tiene sentido desde este sistema explicativo y perceptivo de la situación: de hecho ninguno de los entrevistados pertenece o ha pertenecido a algún sindicato o asociación de parados $^{3}$; a mi pregunta sobre la experiencia asociativa que tenían, la respuesta de uno de los chicos resultó muy ilustrativa:

3 Situación generalizada entre los jóvenes como demuestran los resultados del estudio realizado por el CIS y el Instituto de la Juventud (septiembre 1998) sobre la 
La gente joven tiene una manera de pensar y en general piensan que manifestarse y esa clase de cosas no valen para nada, porque se ha visto muchas veces que todo eso de manifestarte y quejarte en la calle no sirve para nada, no te van a hacer más caso por salir a la calle, las cosas están como están y no vas a crear empleo por ir a la calle, hombre no voy a negar que los sindicatos luchan por algunas cosas y que a veces, tienen su utilidad, pero para nuestro caso particular de encontrar trabajo inmediatamente, no van a hacer una manifestación, las manifestaciones de los sindicatos son por el tema de las condiciones de trabajo y cosas de ese tipo, que sí pueden tener su utilidad para el que tiene ya trabajo, pero a mí que mi problema individual es encontrar trabajo ya no me va a servir para nada [...]

Cuando los problemas se perciben como asuntos de pura competencia individual, las soluciones se plantean también desde una perspectiva exclusivamente individual:

"Yo las soluciones me las he buscao particularmente, no me he ido a ningún colectivo, lo que he hecho ha sido leer muchos libros, aprender a hacer curriculum, buscar direcciones, moverme"; "yo creo que es mejor buscar trabajo individualmente"; "yo cuando estuve en el curso de Secretariado del INEM, nos dijeron que fuésemos un día a un sitio de Comisiones Obreras, que había reuniones para la gente que estaba desempleada para aprender tácticas para buscar tabajo y sitios donde tenías que ir, direcciones, y lo he intentado y nada, lo único que conseguí fueron direcciones de empresas de trabajo temporal y nada más"; "no puedes esperar a que nadie te saque las castañas del fuego, sino que tienes que ser tú, tú te tienes que mover todos los días, levantarte por la manana y irte tú solo individualmente $[\ldots]$.

Esta percepción individualizada del desempleo produce además un efecto culpabilizador en el joven; al haber interiorizado la creencia en la escasez del empleo, cuando logra acceder a un trabajo, su éxito lo interpreta como la contrapartida del fracaso de los que han quedado excluidos. Conseguir un empleo quiere decir, desde este tipo de argumentación, que los demás candidatos quedan eliminados: si alguien consigue un empleo es a costa de que otro no lo consiga. De este modo, se pierde totalmente la perspectiva estructural e institucional del mercado laboral y su incardinación en un sistema económico y político, al mismo tiempo que se consolida el proceso de naturalización e individualización de la experiencia laboral. He aquí cómo lo relataba uno de los jóvenes entrevistados:

Todo el mundo no va a ser el número uno, como te estoy diciendo yo, el que vale vale, lo que quiero decir es que si hay diez personas para un puesto de

Vida cotidiana de los jóvenes: sólo el $2 \%$ declara pertenecer actualmente a un sindicato, el $11 \%$ haber pertenecido, y el $86 \%$ no haber pertenecido nunca. 
trabajo, lo que tienes que intentar, lo que está en tus manos es ser de los mejores... claro que entonces las otras personas van al paro, que es lo que está pasando ahora, hay mucha gente para trabajar y poco trabajo.

No es de extrañar que cuando no se accede a un empleo, pese a los cursos realizados y a la movilización de las redes personales, el sentimiento del joven sea de frustración y de fracaso.

"Tener veintitantos años y no tener trabajo es no contar para nadie, bueno puedes contar para los amigos, la familia, pero socialmente no eres nadie, no tienes posibilidades de futuro, no tienes posibilidades en el presenten; "yo creo que lo que te da tener un trabajo estable es la sensación de libertad, de que sabes que te puedes dedicar a otras cosas, por lo menos de proyectos, de ideas, de pensamiento, pero si lo precario es el trabajo pues parece que todas tus energías, tus fuerzas, las tienes que dedicar a conservar el trabajo o a buscar el siguiente, es como un no vivir, o un vivir muy dedicado a una parte de lo que es la vida, que no termina ahi"; "muchas veces, te faltan hasta las ganas de ir a buscar trabajo, me quedo en la cama y estoy durmiendo y por lo menos me estoy quitando problemas de la cabeza [...]n

El sentimiento de fracaso personal se traduce en expresiones extraídas de las citas anteriores: "no contar", "no vivir", "no ser nadie", pero también en otras recogidas a lo largo de las conversaciones: avivir a salto de mata", "vivir al día", air tirando", "buscarse el pan como sea", "sobrevivir como se puede", "salir del paso", "tener un buen pasar" ${ }^{4}$.

Expresiones todas que denotan negación, desposesión y privación de futuro, de horizonte, en el que proyectar sus deseos, aspiraciones y expectativas:

«El problema de la gente joven es que la gente que se quiere ir de casa no puede irse y eso es lo que nos va a pasar a nosotros, ya no sólo por el incordio de nuestros padres de tenernos en casa ya mayores, sino por nosotros mismos que no te puedes desarrollar como persona, ni hacer tu vida, tener tu familian; "y ya no sólo en el plano económico, sino en valores, en forma de pensar, en proyectos, en ideas, por ejemplo a la gente que le va bien sí que se pueden dedicar a cosas de tipo altruista, a desarrollar la solidaridad, a ayudar a los demás, a ir a museos..., la gente que no tiene recursos se preocupan de ellos mismos porque con eso tienen suficiente, no pueden perder el tiempo en otras personas $o$ ir a museos, son cosas ya como de lujo [...].

4 Sensación de incertidumbre y duda que se refleja también en el $61 \%$ de los jóvenes que contestan estar de acuerdo con la siguiente frase el futuro es tan incierto que lo mejor es vivir al día" (Estudio CIS-Instituto de la Juventud, Juventud y entorno familiar, septiembre-octubre de 1997). 
Precariedad laboral que al impregnar la existencia personal y social marca una diferencia notable con la generación de sus padres: mientras que éstos trabajaban para vivir, para mejorar su nivel de vida, para hacer planes de cara al futuro, para ahorrar y soñar que "el día de mañana" sus hijos no tuvieran que pasar por lo que ellos pasaron (jornadas laborales prolongadas, horas extraordinarias, pluriempleos, emigración...), sus hijos viven para buscar trabajo, no alcanzando a vislumbrar un futuro más allá de la duración del contrato temporal y de la respuesta a la última entrevista realizada o al último curriculum enviado. Es la diferencia entre una generación que creía en el cambio social a través de la militancia colectiva y la acción política y una generación atemorizada por la perspectiva de no lograr incorporarse al mercado laboral y correr el riesgo de aproximarse a los niveles que marcan la exclusión social.

La diferencia entre la generación de nuestros padres y la nuestra, yo la veo en las expectativas, que ellos trabajaban claramente para sacar, para intentar sacar todo adelante, ahora la gente lo que quiere es sobrevivir, buscarse un trabajo e intentar salir adelante y antes, mi padre y toda esa generación hacía un esfuerzo muy grande por sacar lo que es el núcleo familiar, su mujer, los hijos, meterse en la casa, no parar en casa, claro, había mercado de trabajo, había posibilidad de estar trabajando desde la mañana hasta la noche y entonces, con esfuerzo conseguían sacarlo adelante y lo que querían era darles las oportunidades que no habían tenido ellos, la ilusión de todos en que sus hijos fueran a la facultad, tuviesen unos estudios, una preparación que ellos no habían tenido para tener un futuro mejor y ahora es el choque con la realidad, que hay gente muy bien preparada por todas partes y con pocas expectativas de futuro.

La sensación de fracaso aún es mayor si tenemos en cuenta el entorno sociocultural al que pertenecen estos jóvenes, un entorno en el que el empleo, pese a la tesis del "fin del trabajo", sigue siendo fuente de identidad personal y mecanismo de integración social. Un entorno en el que se proclaman la igualdad y la libertad como principios universales y se niega el acceso a los recursos necesarios para desarrollar una existencia autónoma en la que poder idear y realizar un proyecto personal y social. Un entorno en el que se crean muchas expectativas que lejos de representar una amplitud de horizontes y posibilidades de futuro, cuando no se pueden cumplir, se experimenta como el fin de algo que no ha tenido ni tan siquiera la oportunidad de empezar y de ahí, algunas de las expresiones utilizadas por los jóvenes participantes en los grupos de discusión, cuando les propuse que describieran cómo se sentían: "sin ilusiones", "quemado", "descolocado", "hundido", "como gente ya mayor", "te desesperas", "no estás en tu estado normal", "no le ves sentido a las cosas"... Estados de ánimo metaforizados que expresan la sensación de falta 
de libertad y de dominio de las circunstancias, congruente con la visión de la vida y del trabajo como un juego de azar, en el que la suerte a modo de taumaturgo dispone a su antojo de nuestras existencias.

La falta de correspondencia entre los proyectos y las realizaciones, la imposibilidad de construir un horizonte personal y social donde poder proyectar el futuro o en palabras de R. Sennet, el hecho de "no poder estructurar una vida personal coherente; no realizar algo precioso que llevamos dentro; no saber vivir sino meramente existir" (2000: 125), explica la sensación de derrota de estos jóvenes que han sido vencidos en la "partida" principal: la de ser actores-protagonistas de su propia vida.

El fatalismo y determinismo que manifiestan en sus relatos y que se refleja en sus estrategias y prácticas de búsqueda de empleo es un poderoso dispositivo ideológico para desvalorizar cualquier tipo de esperanzas e ilusiones en un futuro diferente por el que merezca la pena luchar:

\footnotetext{
"Tienes que hacerte a la idea de que vas a estar en tu casa toda la vida con tus padres, no poder casarte, no poder viajar, ni tener coche...n; "en la dirección en la que va el tren es en la que hay que subirse, no te vas a subir en la dirección contraria, porque entonces sí que nos estrellamos"; "el empresario busca beneficios y punto, busca lo que tiene que buscar, el beneficio, eso es la actividad empresarial buscar beneficios para ellos y para poder invertir, no se van a preocupar de tu vida o de mi vida, a ellos les da lo mismo"; "las cosas están como están...;; "cuando ves la realidad pues te das cuenta de que hay que intentar buscar lo que sean.
}

Ese "buscar lo que sea" cuyo correlato laboral es "trabajar en lo que sea" representa el mecanismo perfecto de disciplinamiento de los jóvenes, puesto que significa no sólo la interiorización del nuevo axioma de la escasez del trabajo y de la precarización como un estado natural al que hay que doblegarse, sino su coexistencia con la vieja idea de que el trabajo es necesario para vivir. Un trabajo remunerado sigue siendo para los jóvenes el único medio de acceder a un nivel de consumo y a un estilo de vida reconocido socialmente. Tener un coche, adquirir una vivienda, ir de vacaciones, viajar, salir con los amigos, junto con otros signos de identificación y distinción social, siguen siendo bienes a los que sólo se puede acceder si se dispone de un empleo. Su contrapartida es la exclusión social, el olvido, el rechazo, el aislamiento y la estigmatización que sufren los individuos desempleados y sus familias, y que así describieron los participantes de uno de los grupos de discusión:

Aquí hay familias enteras que dependen del subsidio de desempleo y eso es muy, muy delicao, porque encabrona todo lo demás, encabrona cualquier cosa y la gente aguanta y sufre, los padres y los hijos y tira para adelante y si las cosas no 
salen bien ya saldrán mejor, y luego vienen las depresiones, las crisis de todo tipo y todo se junta, la falta de espacio en las casas, la falta de intimidad, la falta de dinero...- y eso que ahora se cubren mejor que antes probablemente las necesidades básicas, se puede comer mejor o peor...- lo que pasa que la presión social es la misma, la presión social antes podía ser si no tenías un pollo que echarte a la cocina y ahora la presión social requiere que tengas una serie de cosas mucho más altas, pero lo que sufre la familia, la presión social por parte del resto es la misma, lo del aparentar, que no es exactamente eso, tener un buen pasar, antes se aceptaba mucho mejor al que estaba en mala situación, yo recuerdo historias de mi madre, de prestar comida a la vecina que venía, oye que me falta esto o tal, que sabías que no era verdad, que era una cosa que le ibas a prestar porque le hacía falta, sin ninguna idea de devolver ni cosa por el estilo, eso ahora se lleva peor,- ahora se castiga mucho más la diferencia, el no mantener un nivel,hay más rechazo por el que está en peor situación, se marcan más las diferencias,- se olvida,- se le deja, se prefiere mirar para otro lado,- ahora es la historia de salir del paso, cada uno a lo suyo [...]

Este extracto de conversación muestra claramente lo que significa la amenaza de la exclusión y explica la angustia de los que ven peligrar su integración social ante las dificultades de acceder a un empleo, así como justifica la aceptación de cualquier trabajo por precario que sea. Aunque, actualmente, la realización de una actividad productiva no elimina necesariamente el espectro de la pobreza ${ }^{5}$, el trabajo sigue siendo considerado como una de las máximas aspiraciones de los jóvenes igual que el paro uno de sus principales temores ${ }^{6}$. Esta situación paradójica en la que por un lado, el trabajo se percibe como un bien escaso y por otro, como el principal medio que permite el acceso a los bienes que eliminan el riesgo de la marginación, es la expresión social de la contradicción inherente a un sistema económico, que si bien puede prescindir de los individuos como trabajadores, al mismo tiempo los necesita como consumidores. Esta contradicción, estructural en su origen, ha sido trasladada del sistema a los sujetos, quienes viven su situación como el resultado de un problema meramente individual. Al asumir el desempleo como el producto de circunstancias personales que dependen de la "buena" o "mala suerte" que se tenga en la vida y no de condiciones estructurales e institucionales,

5 Si tenemos en cuenta los datos referidos a la situación de los cabezas de familias pobres, potencialmente activos en España, encontramos junto a un 55,2\% que están desempleados o en la economía sumergida, a un 44,8\% que están trabajando normalmente y de modo estable (fijos o eventuales), lo que no impide que no salgan de la pobreza (Rojo Torrecilla 1999: 172).

6 El $70 \%$ de los jóvenes señala el paro como su principal temor personal para los próximos años, según los resultados del estudio sobre Juventud y economía, CISInstituto de la Juventud de octubre de 1997. 
desaparece toda posibilidad de movilización colectiva y de lucha política contra el desempleo y la precarización del mercado laboral.

El valor social de la metáfora "la vida es un juego de azar" y "encontrar un trabajo depende de la buena o mala suerte que se tenga" está en que da sentido a la cadena de incoherencias en que se convierte la trayectoria laboral de los jóvenes, quienes son solicitados como consumidores a tiempo completo y trabajadores a tiempo parcial; en su significación como criterio de realidad y verdad para los jóvenes parados. El poder de la metáfora es el efecto de realidad que crea en los sujetos, para quienes su situación es fruto del azar, del destino, y no de las fuerzas económicas que se presentan como ajenas a toda voluntad humana; el proceso de naturalización e individualización de la percepción y experiencia del desempleo elimina cualquier tipo de análisis del mercado de trabajo o de la estructura económica, inhibiendo así las respuestas colectivas y la acción política.

Lakoff y Johnson en la obra ya citada escriben:

Las ideologías políticas y económicas tienen marcos metafóricos. Como todas las otras metáforas, las metáforas políticas y económicas pueden ocultar aspectos de la realidad. Pero en el área de la política y la economía, las metáforas importan más, porque limitan nuestras vidas. Una metáfora en un sistema político o económico puede llevar a la degradación humana en virtud de aquello que oculta (ibid: 281).

Lo que oculta la metáfora objeto de análisis en este artículo es el carácter estructural del desempleo, resultado del fundamentalismo económico para el que los sujetos no tienen más valor que el de simples recursos, que se "gestionan" en función de las necesidades del mercado. La interiorización de la metáfora supone la desposesión y privación de la voluntad y la libertad humanas para oponerse y rebelarse ante situaciones de "degradación", al proyectar como fracaso personal lo que es fruto de la injusticia estructural.

\section{BiBLIOGRAFía CITADA}

BILBAO, ANDRÉs. 1999. El empleo precario. Seguridad de la economía e inseguridad del trabajo. Madrid: Los Libros de la Catarata.

BOURDIEU, PIERRE (dir.). 1999. La miseria del mundo. Madrid: Akal.

CACHÓN, LORENZO (ed.). 1999. Juventudes, mercados de trabajo y políticas de empleo. Valencia: 7 i Mig.

CIS-INSTITUTO DE LA JUVENTUD. Octubre 1997. Juventud $y$ entorno familiar.

CIS-INSTITUTO DE LA JUVENTUD. Octubre 1997. Juventud y economía.

CIS-INSTITUTO DE LA JUVENTUD. Septiembre 1998. Vida cotidiana de los jóvenes. 
DE LUCAS, A. 1994. "Sociedad de consumo o sociedad de mercado: el caso de las comunidades kula". Política y Sociedad 16: 25-36.

GONZÁlEZ GARCíA, JOSÉ M." 1996. "Límites de la racionalidad social: azar, fortuna y riesgo", en A. Pérez-Agote e I. Sánchez de la Yncera (eds.), Complejidad y Teoría social. Madrid: CIS.

LAKOFF, G. y M. JOHNSON. 1991. Metáforas de la vida cotidiana. Madrid: Cátedra.

Martín SerRANo, M. y O. Velarde. 1996. Informe Juventud España 96. Madrid: Instituto de la Juventud.

POLANYI, K. 1989. La Gran Transformación. Crítica del liberalismo económico. Madrid: La Piqueta.

RIVAS RIVAS, ANA M." 1999. "Solidaridad intergeneracional: ¿quién depende de quién?, ¿quién ayuda a quién?.. Sociología del Trabajo 36: 109-133.

ROJO TORRECILLA, EDUARDO. 1999. "Derecho al trabajo, precariedad laboral y exclusión social. Documentación social. Revista de Estudios Sociales y de Sociología Aplicada 114: $167-183$.

SENNET, RICHARD. 2000. La corrosión del carácter. Las consecuencias personales del trabajo en el nuevo capitalismo. Barcelona: Anagrama. 